\title{
Effect Of Pre-TreatmentConditionsAnd VarietalDifferences On The Functional PropertiesOf Sweet Potato Flour
}

\author{
* Osibanjo A. A ${ }^{1}$., Elemo G. $\mathrm{N}^{1}$., Henshaw F.O ${ }^{2}$ and Awonorin S. O ${ }^{2}$. \\ ${ }^{1}$ Federal Institute of Industrial Research, Oshodi, Lagos. Nigeria. \\ ${ }^{2}$ Federal University of Agriculture, Abeokuta. Nigeria
}

\begin{abstract}
To determine theeffect of pre- treatment and varietal differences on the functional properties of orange-fleshed sweet potato flour,five tuber varieties (numbered 1,2,3,4 and 5) were subjected to three treatments namely (i) no treatment (ii) soaking of whole tubers in water at ambient conditions for 6hours and (iii) steam blanching of whole tubers in water for 10minutesA General Factorial design was employed to analyse factor effects andfunctional properties evaluatedwere Water absorption capacity (WAC), Water solubility index (WSI), Dispersibility (D), Bulk density (BD), Fat absorption capacity (FAC) andEmulsifying capacity (EC), though only WSI, D and EC were used for the factor analysis.In terms of WSI,no significant difference was found with the varieties orpre-treatments $(p>0.05)$. ForDispersibility, a significant difference was observed with the varieties ( $p<0.05)$ but not with pre-treatmentsWithrespect to EC, however, a significant difference was observed with the varieties as well aspre -treatments at $p<0.05$.On the whole, varietal differenceswere observed andpre-treatment was found to improve functional properties of some of the tuber varieties investigated in this study.
\end{abstract}

Keywords: Orange - fleshed Sweet Potato, Pre-treatment, Functional properties, Variety, Utilization

\section{Introduction}

Sweet potato (Ipomoea batatas) is an important root crop that is produced in appreciable quantities in Nigeria, who is reported to be the largest producer in Africa with an annual production figure ofabout $3.49 \mathrm{~m}$ tonnes ${ }^{1}$ It is a readily available, cheap and nutrient rich $\operatorname{crop}^{2}$ but not put to much local use because of its natural sweet taste which makes it out of place in many of the local savoury dishes and also because it is difficult to peel. It has, however, been recommended as having great potentials as raw material for the manufacture of a wide range of products ${ }^{3}$

Choice of variety and pre- treatment to ease peeling difficulties have been investigated and reported ${ }^{4}$ The aim of this work is to study the effect of these pre -treatments and varietal differences on the functional properties of sweet potatoflour, so that the natural sweetness of the crop can be explored and utilized appropriately in different food formulations.

Functionalproperties are those physico - chemical properties that influence structure, appearance, texture, viscosity, mouth feel and flavor retention of a product ${ }^{5}$ They can be hydration related or surface related and contribute desirable characteristics to food products, thus affecting utilization and acceptability. Adequate information on the nature and functional properties of sweet potato flour is lacking and until this gap is bridged, the crop may not be of much use despite its considerable potentials.

\section{Methodology}

This research work was carried out at the Federal Institute of Industrial Research, Oshodi (FIIRO) in Lagos, Nigeria.

\subsection{Materials}

Five varieties ofCIP* certified orange - fleshed sweet potato tubers (namely : 199024, 440034, 440140, 440216 andEx- Oyunga and given serial numbers 1,2,3,4 and 5 respectively), were obtained from the University of Ibadan Agronomy Department. They were subjected to different pre-treatments viz (i) No treatment (i.e. controls), (ii) Soaking of whole tubers in water at ambient conditions for 6hours and (iii) Steam blanching of whole tubers for 10 minutes

\subsection{Experimental design and Data analysis}

A General Factorial Design with Analysis of Variance by Design Expert Version $8.0^{6}$ was used to determine the effect of variety and pre-treatment, singly and in combination, on functional properties based on the stated parameters.

\subsection{Functional properties}

These were measured in terms of :

(i) Water absorption capacity (WAC) ${ }^{7}$

(ii) Water solubility index (WSI) ${ }^{7}$ 
(iii) Dispersibility (D) ${ }^{8}$

(iv) Bulk density(BD) ${ }^{9}$

(v) Fat absorption capacity (FAC) ${ }^{10}$ and

(vi) Emulsifying capacity $(\mathrm{EC})^{10}$

Measurements were done in triplicates and mean values presented.

*CIP - International Potato Centre, Lima, Peru. South America

\section{Results}

Theresults from this study are presented in Tables $1-2$ and Figures. $1-6$

Table1: Functional Properties of Flour Samples

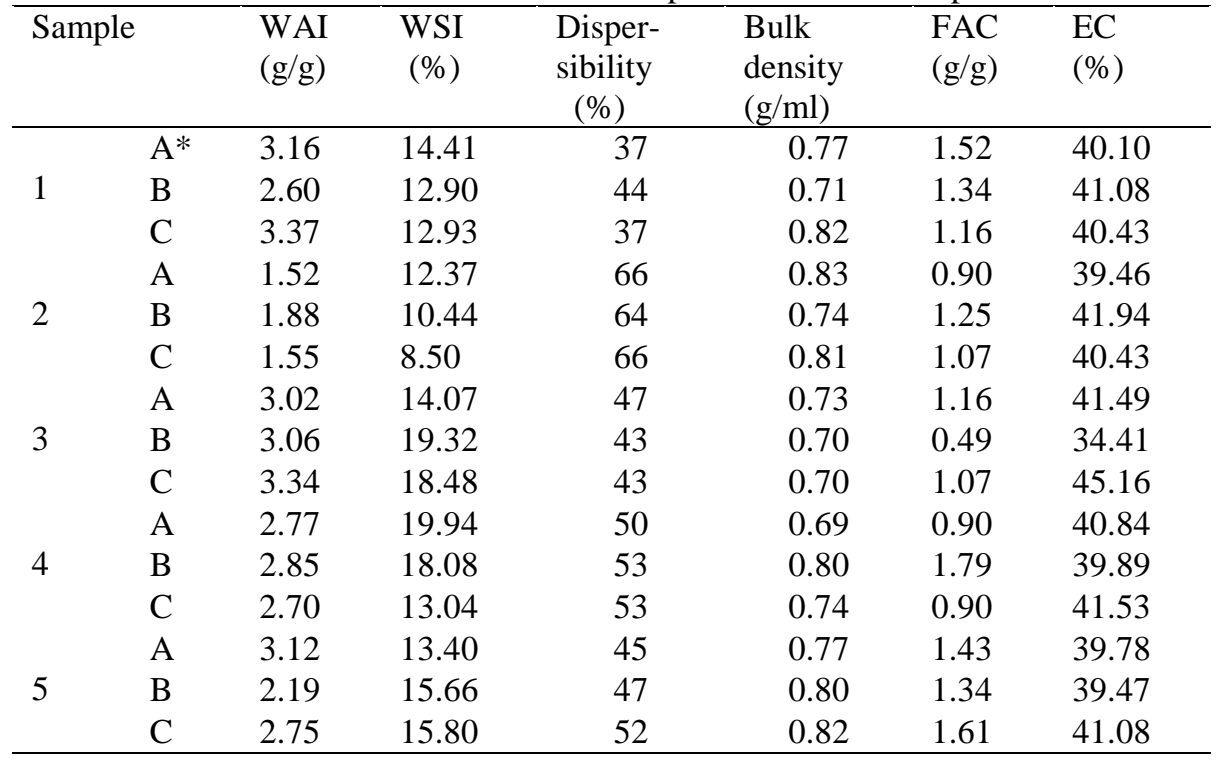

* Notations 1,2,3,4\& 5 are the different varieties; A- notreatment,

$\mathrm{B}$-soaking in water, and C - steam blanching

Table 2 : Model coefficients for functional properties

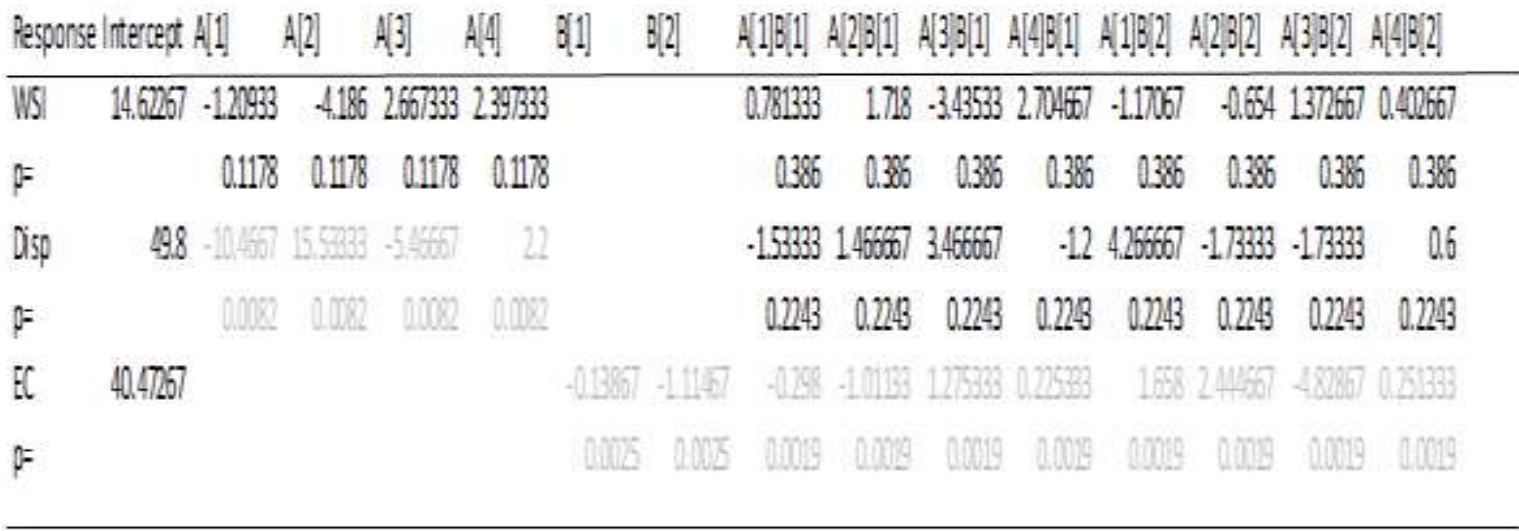

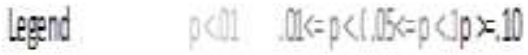

( $\mathrm{p}$ values greater than 0.05 are not significant) 


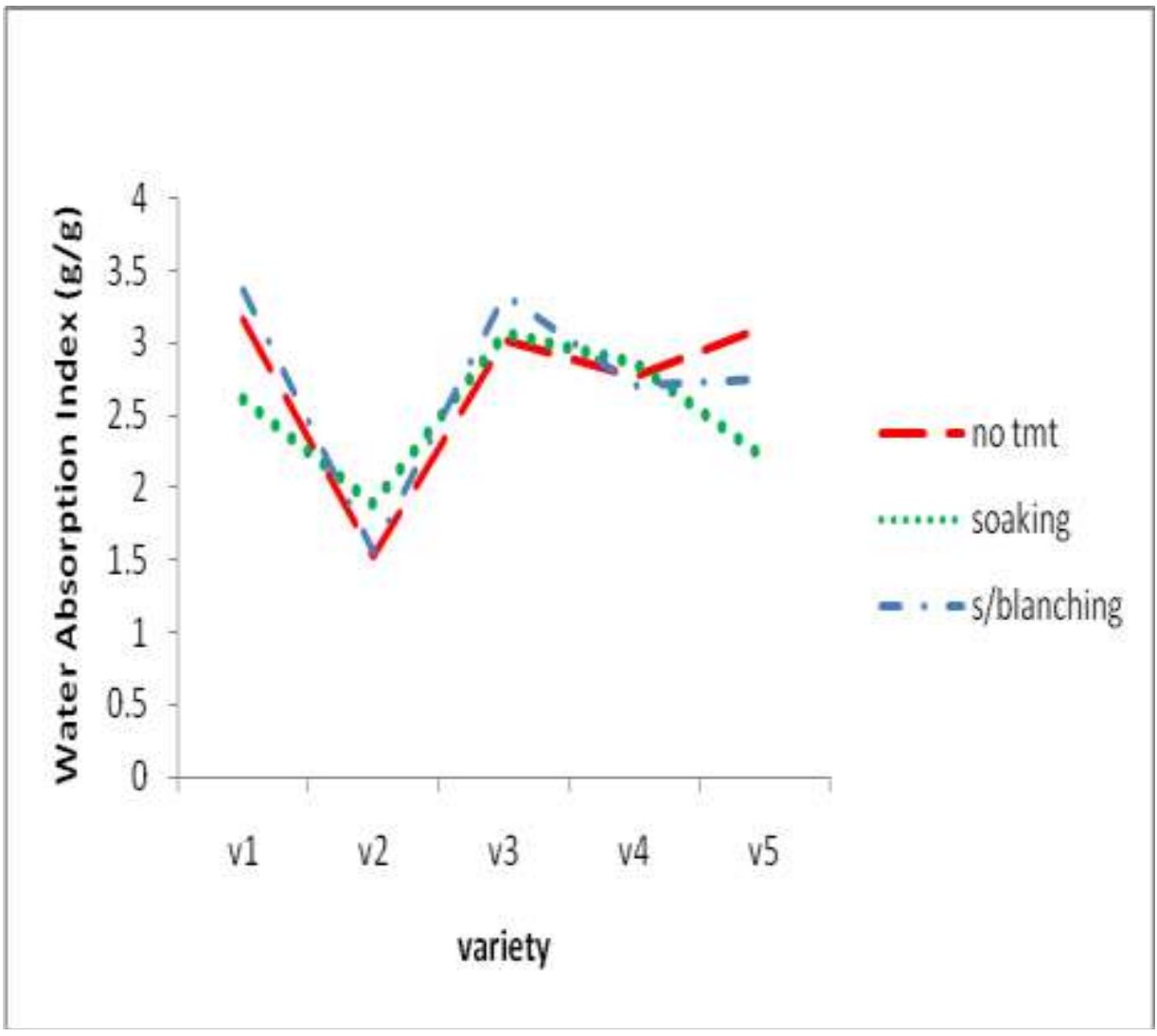

Figure 1: Variety / Treatment effect for Water Absorption Index

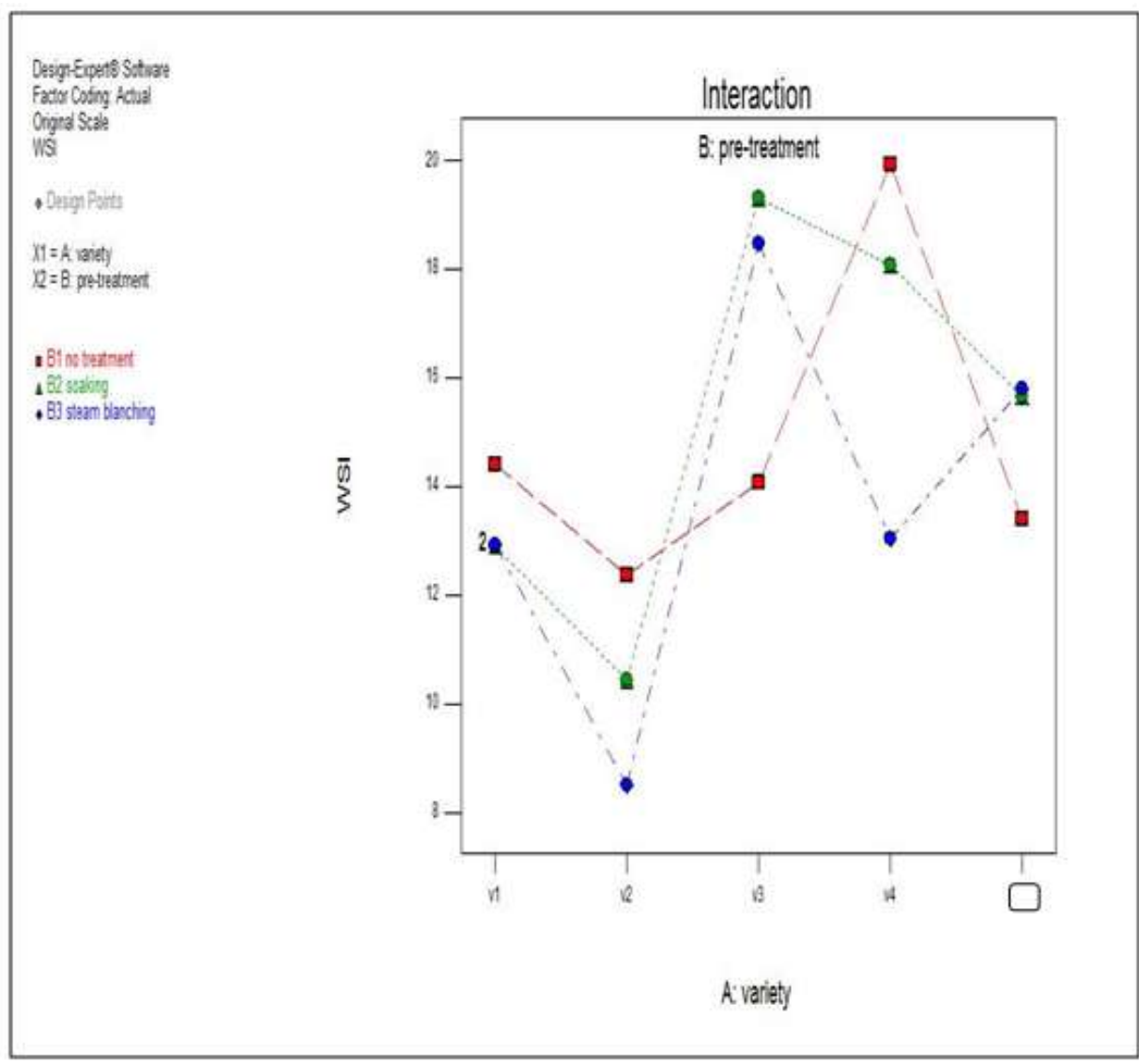

Figure 2 : Variety / Treatment effect for Water Solubility Index 


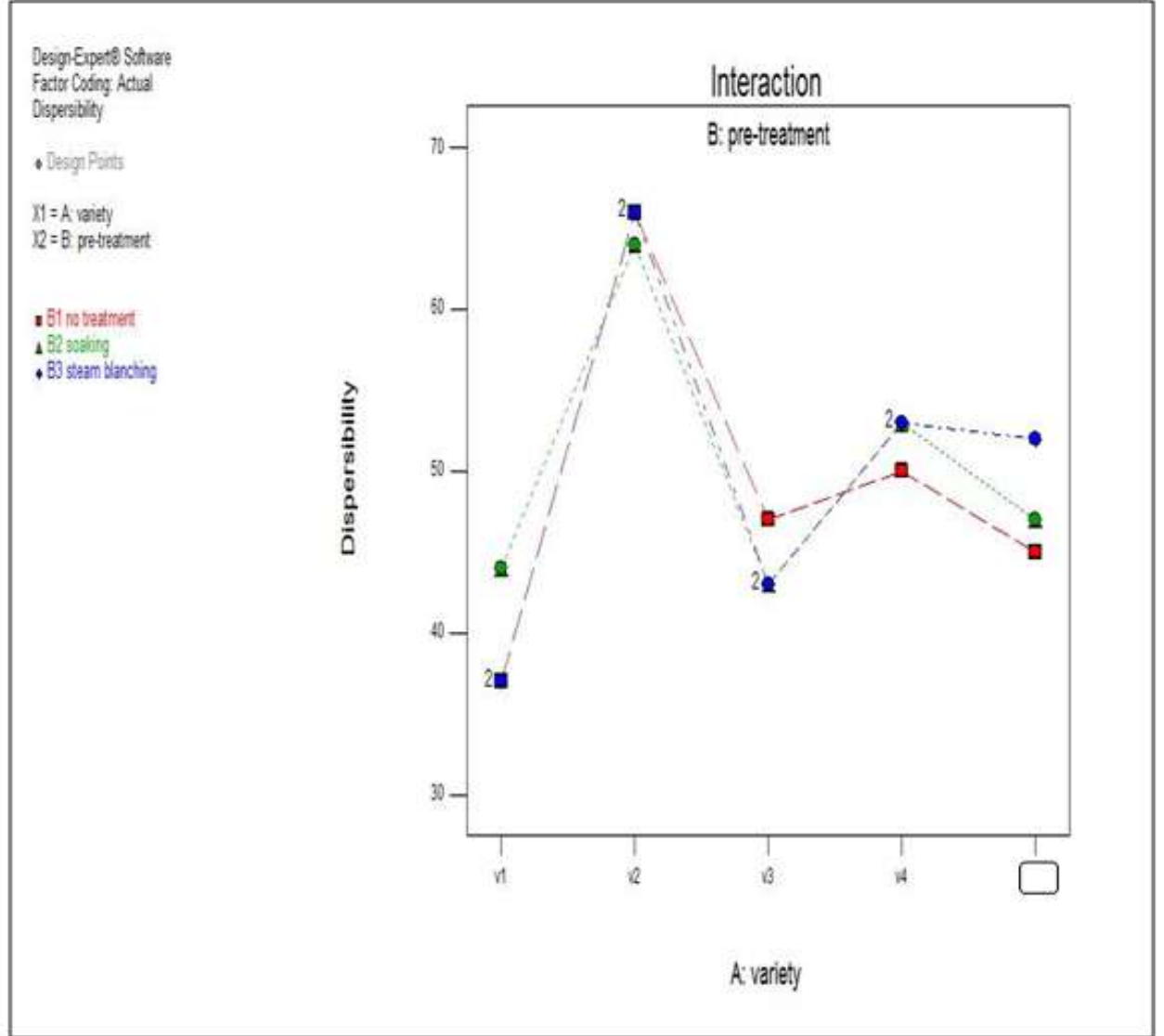

Figure 3 : Variety / Treatment effect for Dispersibility

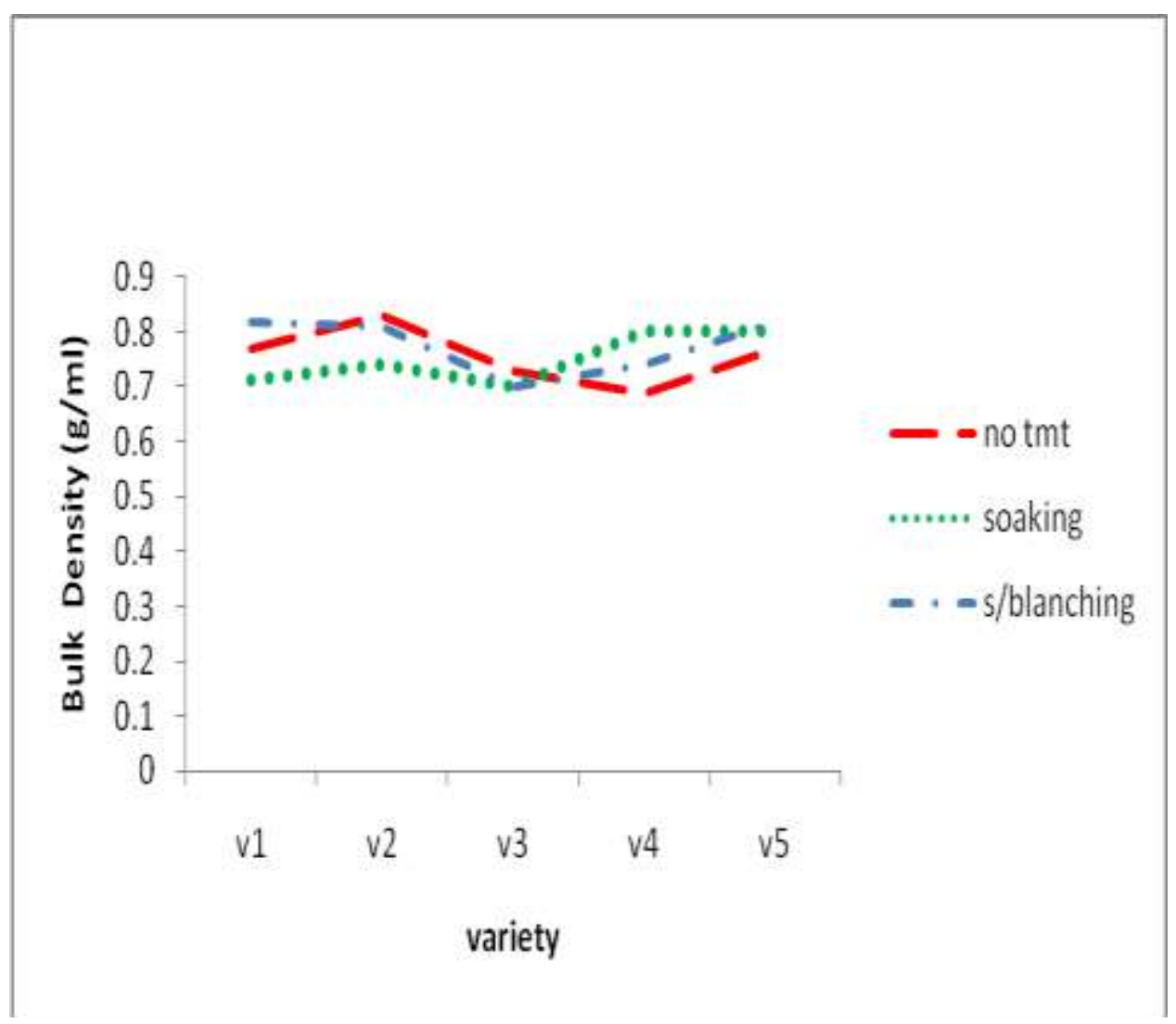

Figure 4 : Variety / Treatmenteffect for Bulk Density 


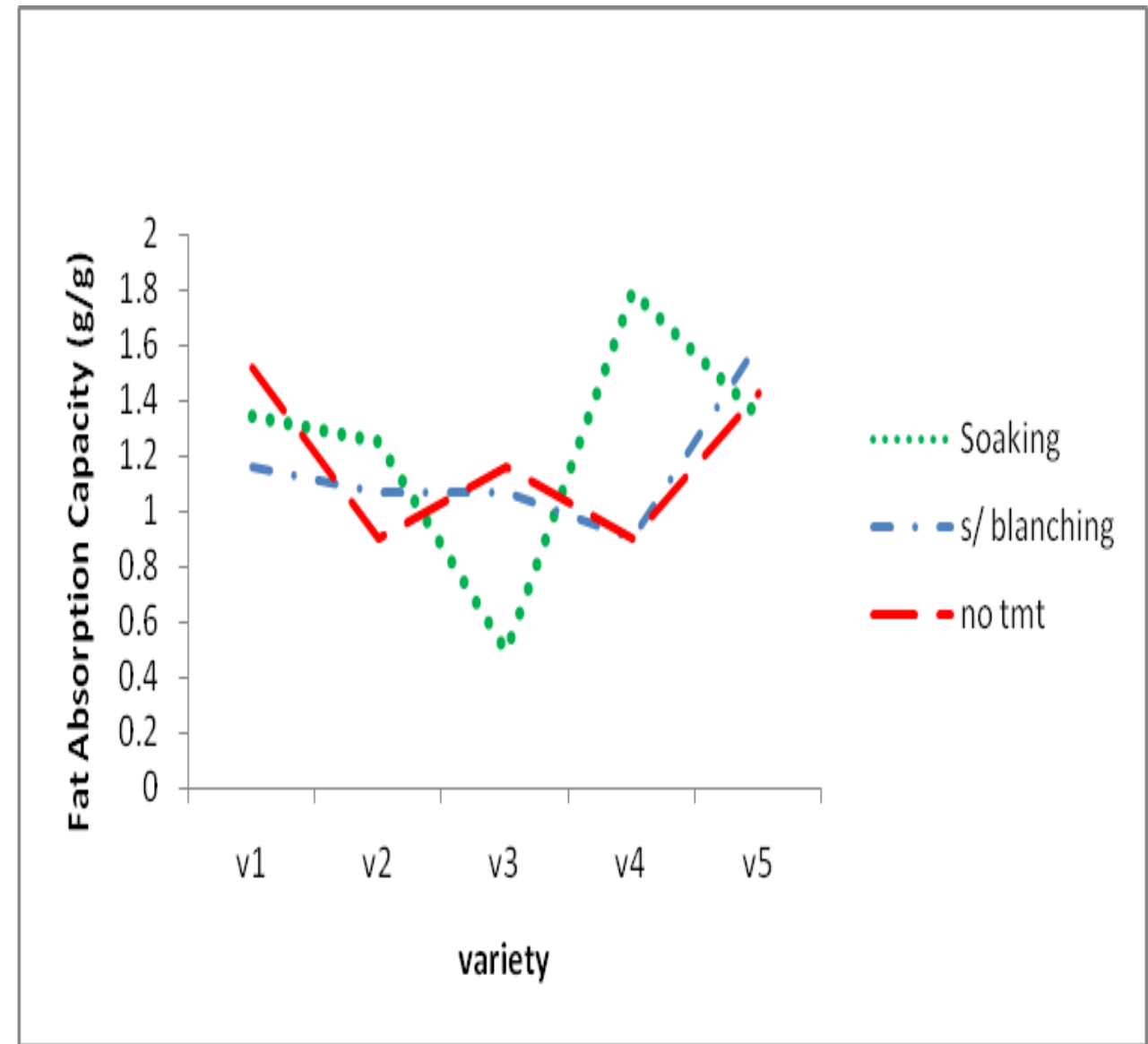

Figure 5 : Variety / Treatment effectfor Fat Absorption Capacity

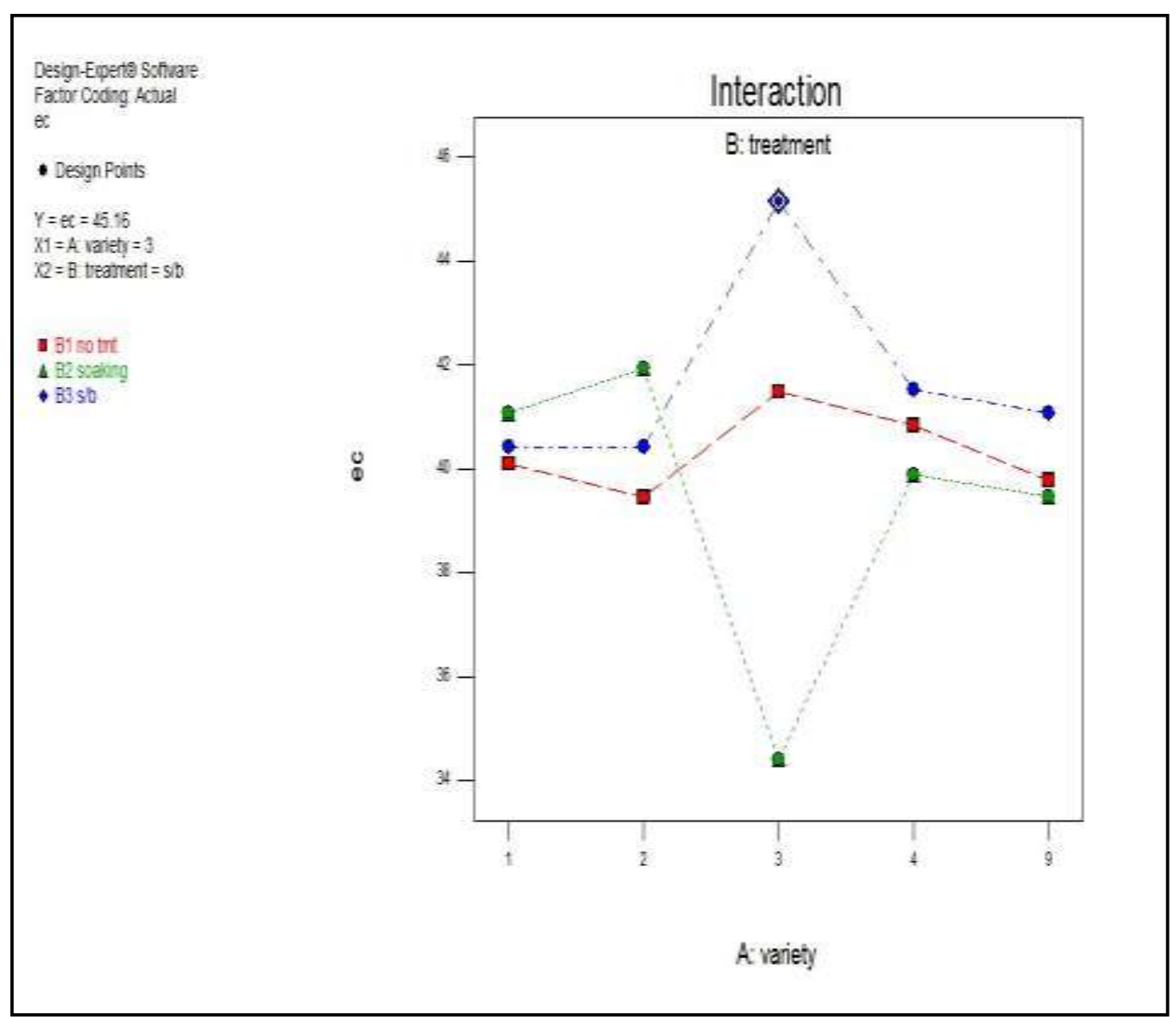

Figure 6: Variety /Treatment effect for Emulsifying Capacity 


\subsection{Functional properties}

\section{Discussion}

The functional properties of the different varieties, subjected to the different pre-treatments are presented in Table 1. The A's are the controls; the B's are soaked while the C's are steam blanched samples.

Water Absorption Index (WAI) in g/gis a measure of the ability of the samples to take up water, therebyindicating the water available for gelatinization and other physico-chemical changes. Values ranged from 1.52 in $2 \mathrm{~A}$ to 3.37 in $1 \mathrm{C}$. Higher WAI values indicate loose association of starch polymers in the native granule and imply that more water will be required during reconstitution. Generally, variety 2 followed by 4 showed lower WAI values (Fig.1) while 1, 3 and 5 showed higher values, indicating the tendency of these flours to be gelatinized and well cooked. Pre-treatment reduced WAI in variety 5 but increased it in 3 . Specifically, soaking reduced WAI in varieties 1 and 5 while steam blanching reduced it in 5

Water Solubility Index (WSI)is an indication of the ability of the sample to leach soluble components into water,thereby affecting taste and chew ability of the resulting product. Values recorded ranged from $8.50 \%$ in $2 \mathrm{C}$ to $19.94 \%$ in $4 \mathrm{~A}$ (Fig.2). Ahigher WSI as observed in variety 4 , therefore, imply the tendency for a transfer of sweet potato flavour and this can be appreciable in masking or reducing undesirable taste effects from other components in a given product. Pre-treatment reduced WSI values in varieties 1,2 and 4 but gave an increase in 3 and 5.

Dispersibilityranged from $37 \%$ in $1 \mathrm{~A}$ and $1 \mathrm{C}$ to $66 \%$ in $2 \mathrm{~A}$ and $2 \mathrm{C}$ (Fig.3). When the varieties were compared together,number 2 showed higher dispersibility values, 1 showed lower values while the others were in between The higher the dispersibility, the better is the ability of a flour material to be reconstituted. This parameter is of importance and will influence consistency during mixing. Pre-treatment increased dispersibility in varieties 1,4 and 5 but reduced it in 2 and 3 .

Bulk Density (BD) in $\mathrm{g} / \mathrm{ml}$ is a measure of particle heaviness determined as mass per unit volume and ranged from 0.69 in $4 \mathrm{~A}$ to 0.83 in $2 \mathrm{~A}$. As shown in Fig.4, varieties 4 and 3 seemed to be lighter while 2 seemed heavier with 1 and 5 in between.Higher bulk density figures (as observed in variety 2) indicate the ability not only to disperse in water during processing but also to occupy a smallerspace for a given mass of sample. These values therefore have implications for packaging. Pre-treatment decreased BD in varieties 2 and 3 but increased it in 4 and 5 while in 1, BD was reduced by soaking but increased by steam blanching.

Fat Absorption Capacity (FAC) in $\mathrm{g} / \mathrm{g}$, which is an indication of the ability of a sample to take up fat, ranged from 0.49 in 3B to 1.79 in 4B. Varieties 1 and 5 generally showed higher FAC while 2 and 4 showed lower values (with the exception of the soaked sample, 4B) as seen from Fig.5. Pre-treatment increased FAC in varieties 2 and 4 but reduced it in 1 and 3 while in variety 5, the FAC was reduced by soaking but increased by steam blanching. The ability to absorb and mix with fat is important as fat is one of the key materials in many food formulations and has pronounced effect on the flavour.

Emulsifying Capacity (EC) was least in 3B with $34.41 \%$ and highest in 3C with $45.16 \%$ (Fig.6). This parameter indicates the ability of the sample to be able to form emulsions and consequently a stable product, arising from the uniform distribution of its particulates.Generally, pre-treatment increased the EC in varieties 1 and 2. Specifically, steams blanching increased EC in all the varieties likely as a result of the heating, as processes involving fat are enhanced at increased temperature.

\subsection{Factor Analysis}

This was done using three of the measured parameters, considered to be very pertinent, (WSI, Dispersibility and EC). The results are summarized in Table 2.

From the model coefficients (values greater than 0.05 are not significant), it can be observed that in terms of the water solubility index at $p>0.05$, there was no significant difference in water solubility index with the varieties and pre-treatments.

WithDispersibility, there was significant difference with the varieties $(p<0.05)$ but not with pretreatments.

With respect to emulsifying capacity, a significant difference was observed with the varieties as well as pretreatments $(\mathrm{p}<0.05)$.

This means that, on the whole,varietal differences wereobservedand pre-treatmentcan improve the functional properties of some tuber varieties investigated in this study,

\section{Conclusion}

This study has shown that the orange-fleshed sweet potato varieties investigated were significantly different in EC and Dispersibility but not in Water Solubility Index.Steam blanching also significantly improved EC but not WSI and Dispersibility. The information generated is very relevant in the choice of sweet potatotuber variety and pre-treatment for specific food processing applications. 


\section{Acknowledgements}

The following are hereby greatly acknowledged for their contributions in various ways:

- The Federal Institute of Industrial Research, Oshodi (FIIRO), Lagos. Nigeria, for support with respect to funds and facilities released for the work.

- Professor M. Akoroda of the University of Ibadan Agronomy Department, for the gracious provision of the sweet potato varieties used in this study.

- Professor L. Sanni, Dr P. Sobukola and Dr T. Shittu, all of the FST Department of FUNAAB, Abeokuta. Nigeria for their invaluable help.

- Messrs Kosoko S.B and Owolabi S.O of FIIRO, Lagos, who helped with flour processing and analysis.

\section{References}

[1]. FAO,Food and Agriculture Organization of the United Nations Statistics Division. www.fao.org(October, 2009)

[2]. J.A.Woolfe, Sweet Potato-An untapped food resource(Cambridge University Press. Cambridge, UK,1992)

[3]. FAO,Sweet potato production(Food and Agriculture Organization Publication. Rome, Italy, 2002)

[4]. A.A.Osibanjo and S.O.Awonorin, Effect of pre -treatment conditions and varietal differences on the peeling characteristics of orange-fleshed sweet potato. Continental Journal of Food Scienceand Technology, 8, 1, 2014, 1-7

[5]. C.V. Morr and E.W. Ha, Whey protein concentrates and isolates - processing and functional properties. CriticalReviewsin Food Science and Nutrition, 33, 6, 1993, 431

[6]. Stat - Ease, Design Expert statistical software, version 8.0 (Stat - Ease Co, Minneapolis, USA, 2010)

[7]. R.A.Anderson, Water absorption, solubility and amylograph characteristics of roll cooked small grain products. Cereal Chemistry,59, 1982, 265-270

[8]. K.D. Kulkarni, D.N. Kulkarni and U.M. Ingle,Sorghum Malt Based Formulations - preparation, functional properties and nutritive value. Food and Nutrition Bulletin, 13, 4, 1991, 322-327

[9]. J.C. Wang and J.E.Kinsella, Functional property of Novel Protein, Alfafa Leaf Protein. Journal of Food Science, 4, 1976, 286-296

[10]. F.W.Solsulski,E.S. Humbert, K, Buiand J.D. Jonnes,Functional properties of rapeseed flours, concentrates and isolates. Journal of Food Science, 41, 1976, 1349

[11]. L.R. Beuchat, J.P. Cherry and M.R.Quinn,. Physico-chemical properties of peanut flour as affected by proteolysis.Jornal ofAgricultural and Food Chemistry, 39, 1975, 344 